\title{
Salt Used for the National School Nutrition Program (NSNP) in Rural Schools of Limpopo Province, South Africa, has Adequate Levels of Iodine
}

\author{
Mpho Ramugondo, ${ }^{1}$ Lindelani Fhumudzani Mushaphi, ${ }^{2}$ and Ngoako Solomon Mabapa ${ }^{2}$ \\ ${ }^{1}$ Department of Health, Nutrition Section, University of Venda, Mopani District 1391, Phalaborwa, South Africa \\ ${ }^{2}$ Department of Nutrition, School of Health Sciences, University of Venda, Thohoyandou 0950, South Africa \\ Correspondence should be addressed to Ngoako Solomon Mabapa; solomon.mabapa@univen.ac.za
}

Received 20 January 2021; Revised 8 April 2021; Accepted 2 May 2021; Published 1 June 2021

Academic Editor: Danni Zheng

Copyright (c) 2021 Mpho Ramugondo et al. This is an open access article distributed under the Creative Commons Attribution License, which permits unrestricted use, distribution, and reproduction in any medium, provided the original work is properly cited.

\begin{abstract}
Background. Salt iodisation is considered the most effective long-term public health intervention for achieving optimal iodine nutrition. Effective salt iodisation is a prerequisite for the sustainable elimination of iodine deficiency disorders. The aim of this study was to determine iodine concentration of salt used for the National School Nutrition Program (NSNP). Methods. A crosssectional study was conducted in 359 food handlers from Vhembe and Mopani districts of Limpopo Province, South Africa. The questionnaire was administered to solicit data on demographic information, general questions on salt fortification, and iodine nutrition knowledge. After the interviews, two tablespoons of salt used for the NSNP food preparation was collected from 318 schools in small zip-lock plastic bags. The salt samples were coded and stored at room temperature and protected from light and moisture until the time of analysis. Salt iodine concentrations were determined at the North-West University (NWU) in Potchefstroom by means of the iCheck test method. Results. The median iodine concentration of both Mopani ( $31.65 \mathrm{ppm})$ and Vhembe (32.56 ppm) districts signified adequate iodine levels. Of 318 salt samples, 113 (71\%) samples in Mopani and 104 (65\%) in Vhembe had an iodine concentration of 15-64 ppm. A few (6\%) food handlers in Mopani and almost half (45.9\%) in Vhembe could correctly identify iodated salt as the main source of iodine. Almost half of the food handlers (\%) in Mopani and 36.5\% in Vhembe did not know which part of body needs iodine for functioning. Conclusion. More than 20 years after the implementation of the USI program, the result of the study shows that the international goal of $90 \%$ coverage is still far from being realised.
\end{abstract}

\section{Introduction}

Malnutrition is a risk factor for early mortality and morbidity in children and adolescents [1]. Malnutrition and hunger accounts for nearly half of the death rate of children worldwide, with approximately $26 \%$ of undernourished children residing in Africa [2]. An estimated one-fifth (20\%) of the total population comprises those of school age. It is said that approximately $25 \%$ of all children in developing countries are vitamin A deficient, whilst other nutrients most likely to be deficient in school aged children are reportedly iron and iodine, with the prevalence rates of the latter being between $35 \%$ and $70 \%$ [3-7]. Iversen et al. [5] report that undernutrition particularly affects young children residing in rural areas of the country.
Nutrients are not only important for growth and development but also offer children with energy to perform physical and metabolic functions [8]. Nutrition influences the efficiency of educational programmes [9]. Thus, adequate nutrition is vital during the school-age years because nutrition and health influences a child's cognitive development $[3,10]$. Children lacking certain nutrients in their diet and who suffer from persistent hunger, parasitic infections, or other nutrition-related diseases are likely to have reduced potential for learning compared to healthy, well-nourished children [11]. Nutrient deficiencies account for the inability of children to achieve their full mental and physical potential because of stunted growth, low physical work capacity, reduced IQ, and a lower resistance to infection [4]. 
In response to malnutrition, shortly after independence in 1994, the South African government initiated the Primary School Nutrition Programme (PSNP) under the purview of the Department of Health to promote and advocate for malnutrition control, nutritional education, and dietary guidelines in children from low socioeconomic status [5]. The programme was renamed the National School Nutrition Program (NSNP), and implementation was transferred to the Department of Education in 2004 to strengthen action and buy in. The NSNP was introduced as a vehicle for transporting micronutrients such as iron, iodine, and vitamin A to school-aged children [12]. The deficiencies of the three micronutrients of public health significance are iron deficiency anaemia (IDA), iodine deficiency disorders (IDD), and vitamin A deficiency (VAD). Iodine deficiency holds a notorious place among the micronutrient deficiencies which now poses a major worldwide health problem as it is the leading cause of both thyroid and brain abnormalities in children [13].

Salt iodisation is considered the most effective long-term public health intervention for achieving optimal iodine nutrition [14]. Effective salt iodisation is a prerequisite for the sustainable elimination of iodine deficiency disorders. In South Africa, direct and indirect evidence of continued endemic goitre and iodine deficiency led, in 1995, to the introduction of mandatory iodisation of table salt at an iodine concentration of 40-60 ppm. In 2007, the revision of the regulation led to a bigger acceptable range of 35-65 mg iodine/kg salt. Most studies have determined the iodine concentration of household salt but neglected the salt used in the NSNP. This observation underlines the need to determine the iodine concentration of salt used in the NSNP. The main aim of the present study was to determine the iodine concentration of salt used in the NSNP. This may assist in explaining the excessive urinary iodine concentration (UIC) that has been reported recently in South African school children. The secondary aim was to determine the knowledge of food handlers about iodine nutrition and salt iodisation.

\section{Methods}

2.1. Sample Design. The study was conducted in selected schools of Mopani and Vhembe districts receiving the NSNP. The Mopani District is situated in the north-eastern part of Limpopo Province. It is the second biggest of the five districts in Limpopo Province. According to the 2016 community survey, it has an estimated population of 1159185 of whom the majority speak Xitsonga and Northern Sotho. There are 16 urban areas (towns and townships), 354 villages (rural settlements), and a total of 125 wards. There are 562 schools on the NSNP in the Mopani District. On the other hand, the Vhembe District is a category C municipality located in the northern part of Limpopo Province. The district has an estimated population of 1294722 of whom the majority speak Tshivenda and Xitsonga, and the settlement pattern is largely rural with approximately 774 dispersed villages [15]. There are 968 schools on the NSP in the Vhembe District.
Simple random sampling was used to select schools that were included in the sample. A list of schools (both secondary and primary) was obtained from the Departments of Education in Vhembe and Mopani districts. The target population was food handlers employed in schools receiving the NSNP from the two districts. Food handlers are persons responsible for preparing meals for school children and preventing outbreaks of food-borne diseases in schools by adhering to food safety guidelines. A total of 359 food handlers (Mopani $=200$ vs. Vhembe $=159$ ) were conveniently selected from 318 schools of the two districts. In Mopani, the principals insisted that all food handlers participate in the study, hence an extra 41 food handlers. The two districts were selected based on their history of reported cases iodine deficiency. The study's population was from both rural and urban areas. Food handlers in schools receiving the NSNP in the Mopani and Vhembe districts, 18 years and above, were appointed formally by the school governing body and trained before presuming duties as food handlers and were included in the study. Voluteers and relatives who were standing in for food handlers on the day of data collection were excluded from the study. The reason for the exclusion was the fact that they did not receive training.

2.2. Data Collection. Data were collected at the school sites from May 2017 to March 2018. An existing validated researcher-administered questionnaire on knowledge of iodine in the South African adult population [15-17] was used to gather information on iodine nutrition knowledge of food handlers. The questionnaire was administered to solicit data on demographic information, general questions on salt fortification, and iodine nutrition knowledge. The questionnaire was translated into the local languages (Tshivenda, Northern Sotho, and Xitsonga) by the researchers. An expert from the Department of Languages was consulted to translate the questionnaire back to English, and the two were compared. After completing the questionnaire, two tablespoons of salt used for the NSNP food preparation was collected from 318 schools in small plastic zip-lock bags. The salt samples were coded and stored at room temperature and protected from light and moisture until the time of analysis.

The level of knowledge was asssessed using the iodine nutrition knowledge test. The following scores from Umalusi were used to classify the level of knowledge of food handlers: $0-29.9 \%=$ poor; $\quad 30-49.9 \%=$ fair; $\quad 50-69.9 \%=$ good; $70-89.9 \%=$ very good; and $90-100 \%=$ excellent (https:// www.umalusi.org.za/docs/research/2013/nsc_pass.pdf).

2.3. Measurement of Iodine Concentration in Salt by iCheck. Salt iodine concentrations were determined in the iodine laboratory at the North-West University (NWU) in Potchefstroom by means of the iCheck test method [18]. A total of 318 salt samples were analysed representing 100\% successfully analysed samples. The analysis was performed in duplicates. The procedure is outlined as follows: 
TABle 1: Sociodemographic information of participants.

\begin{tabular}{|c|c|c|c|c|}
\hline \multirow[t]{2}{*}{ Sociodemographic information } & \multicolumn{2}{|c|}{$\begin{array}{c}\text { Mopani } \\
\text { district }\end{array}$} & \multicolumn{2}{|c|}{$\begin{array}{l}\text { Vhembe } \\
\text { district }\end{array}$} \\
\hline & $\mathrm{N}$ & $\%$ & $\mathrm{~N}$ & $\%$ \\
\hline \multicolumn{5}{|l|}{ Age } \\
\hline $18-25$ & 6 & 3 & 3 & 1.9 \\
\hline $26-35$ & 60 & 30 & 52 & 32.7 \\
\hline $36-45$ & 82 & 41 & 68 & 42.8 \\
\hline 46 and above & 52 & 26 & 36 & 22.6 \\
\hline \multicolumn{5}{|l|}{ Level of education } \\
\hline Never attended & 13 & 6.5 & 6 & 3.8 \\
\hline Grade 1-7 & 51 & 25.5 & 14 & 8.8 \\
\hline Grade $8-12$ & 128 & 64 & 131 & 82.4 \\
\hline College/tertiary & 8 & 4 & 8 & 5 \\
\hline \multicolumn{5}{|l|}{ Marital status } \\
\hline Single & 88 & 44 & 66 & 41.5 \\
\hline Married & 96 & 48 & 69 & 43.4 \\
\hline Divorced & 4 & 2 & 11 & 6.9 \\
\hline Living with partner & 12 & 6 & 13 & 8.2 \\
\hline \multicolumn{5}{|l|}{ Household income } \\
\hline Less than R1000 & 3 & 1.5 & 3 & 1.9 \\
\hline R1001-R2000 & 165 & 82.5 & 105 & 66 \\
\hline R2001-R3000 & 31 & 15.5 & 40 & 25.2 \\
\hline R3001-R4000 & 0 & 0 & 6 & 3.8 \\
\hline R4001-R5000 & 1 & 0.5 & 5 & 3.1 \\
\hline \multicolumn{5}{|c|}{ Do you have the child at this school you are working? } \\
\hline Yes & 188 & 94 & 152 & 95.6 \\
\hline No & 12 & 6 & 7 & 4.4 \\
\hline \multicolumn{5}{|l|}{ How many children do you have? } \\
\hline None & 7 & 3.5 & 3 & 1.9 \\
\hline $1-2$ & 58 & 29 & 48 & 30.2 \\
\hline $3-4$ & 89 & 44.5 & 76 & 47.8 \\
\hline 5 or more & 46 & 23 & 32 & 20.1 \\
\hline \multicolumn{5}{|c|}{ Were you given nutrition training before working as a food handler? } \\
\hline Yes & 147 & 73.5 & 93 & 58.2 \\
\hline No & 53 & 26.5 & 66 & 41.8 \\
\hline \multicolumn{5}{|l|}{ How long was the training? } \\
\hline 1 day & 47 & 23.5 & 69 & 43.4 \\
\hline 2 days & 13 & 6.5 & 12 & 7.5 \\
\hline 3 days & 11 & 5.5 & 1 & 0.6 \\
\hline A week & 54 & 27 & 9 & 5.7 \\
\hline Other & 24 & 12 & 3 & 1.9 \\
\hline Do not know & 51 & 25.5 & 65 & 40.9 \\
\hline \multicolumn{5}{|l|}{ Topic covered during training } \\
\hline Food handling & 93 & 46.5 & 55 & 34.6 \\
\hline Food safety and hygiene & 5 & 2.5 & 37 & 23 \\
\hline Nutrition & 1 & 0.5 & 1 & 0.6 \\
\hline Other & 0 & 0 & 1 & 0.6 \\
\hline Do not know & 101 & 50.5 & 65 & 40.9 \\
\hline
\end{tabular}

First step: the salt was diluted with distilled water. The sample per analysis was $1.0 \mathrm{~mL}$, the concentration range was $>3 \mathrm{ppm}(\mathrm{mg} / \mathrm{kg})$, and the minimum dilution factor was $1: 3$.

Second step: the sample was injected in the ready-touse reagent vial, and if the solution changed colour to purple, it indicated that iodine was present.
Third step: the diluted solution was then analysed using the photometric determination of iodine colorimetric reaction, the units displayed on the iCheck test device were in $\mathrm{mg} / \mathrm{L}$, the linear range was set on $1.0-13.0 \mathrm{mg} /$ $\mathrm{L}$, and the time per analysis was $<10$ minutes.

The iodine concentrations were classified as oniodised (<5 ppm), inadequately iodised (5-14.9 ppm), adequately iodised (15-64.9 ppm), more than adequately iodised ( $\geq 65-79.9)$, and excessively iodised ( $\geq 80 \mathrm{ppm}$ ) [19].

2.4. Statistical Analysis. The data were entered into Microsoft excel spread sheet and exported to the Statistical Package of Social Science (SPSS). The data were analysed using SPSS version 25 , and they were expressed as means, standard deviation, median, and interquartile ranges. For categorical data, the percentages and number of samples are presented. To compare differences between Mopani and Vhembe districts, the Mann-Whitney $U$ test and independent $t$-tests were used. $p<0.05$ was considered statistically significant.

\section{Results}

A total of 359 food handlers were recruited and completed the study. Table 1 shows the age, level of education, marital status, household income, and number of children. The age of the participants ranged from 18 years to 46 years and above. With regard to the level of education, a majority (Mopani $=64 \%$ vs. Vhembe $=82.4 \%$ ) of food handlers had grades 8-12 in both districts. The marital statuses, single and married, had almost equal percentages in both districts. A majority of food handlers from both districts (Mopani $=82.5 \%$ vs. Vhembe $=66 \%$ ) had an income ranging from R1001 to R2000. Almost all food handlers from both districts had children in the school they are working in (Table 1).

Of 359 food handlers, 147 (73.5\%) in Mopani and 93 (58.2\%) in Vhembe were trained before they were appointed as food handlers. The training period ranged from one day to a week (Table 1). Half of food handlers (50.5\%) in Mopani and $40.9 \%$ in Vhembe did not know which topics were covered during training.

3.1. The Iodine Content of NSNP Salt. A total of 318 salt samples were collected from Mopani and Vhembe districts. The number of salt samples collected from Mopani and Vhembe districts was 159 , respectively. The median iodine concentration of both Mopani (31.65 ppm) and Vhembe $(32.56 \mathrm{ppm})$ districts signified adequate iodine levels. There was no significance difference observed between the medians $(p=0.428)$ (Table 2).

Of the 318 salt samples, 113 (71\%) samples in Mopani and $104(65 \%)$ in Vhembe had an iodine concentration of 15-64 ppm (Table 3). Few samples in Mopani (9\%) and Vhembe (11\%) were noniodised. Further fewer samples in Mopani (8\%) and Vhembe (4\%) were excessively iodised (Table 3). 
TABle 2: Iodine content mean values for Mopani and Vhembe districts.

\begin{tabular}{lccc}
\hline District & Mean \pm SD $(N=159)$ & Median $(N=159)$ & $p$ value \\
\hline Mopani & $36.53 \pm 27.88 \mathrm{ppm}$ & $31.65 \mathrm{ppm}($ IQR: $23.50-43.30 \mathrm{ppm})$ & 0.428 \\
Vhembe & $34.24 \pm 23.46 \mathrm{ppm}$ & $32.56 \mathrm{ppm}($ IQR:14.41-51.51 ppm) \\
\hline
\end{tabular}

TABle 3: Distribution of salt by iodine concentration.

\begin{tabular}{|c|c|c|c|c|}
\hline \multirow{2}{*}{ Iodine content categories } & \multicolumn{2}{|c|}{ Mopani district } & \multicolumn{2}{|c|}{ Vhembe district } \\
\hline & $N$ & $\%$ & $N$ & $\%$ \\
\hline$<5$ ppm (noniodised) & 14 & 9 & 18 & 11 \\
\hline 5-14 ppm (inadequately iodised) & 13 & 8 & 25 & 16 \\
\hline $15-64 \mathrm{ppm}$ (adequately iodised) & 113 & 71 & 104 & 65 \\
\hline $65-79.9 \mathrm{ppm}$ (more than adequately iodised) & 7 & 4 & 6 & 4 \\
\hline$\geq 80 \mathrm{ppm}$ (excessively iodised) & 12 & 8 & 6 & 4 \\
\hline Total & 159 & 100 & 159 & 100 \\
\hline
\end{tabular}

TABLE 4: General questions on the salt fortification.

\begin{tabular}{|c|c|c|c|c|}
\hline \multirow[t]{2}{*}{ Description of questions } & \multicolumn{2}{|c|}{ Mopani District } & \multicolumn{2}{|c|}{$\begin{array}{l}\text { Vhembe } \\
\text { District }\end{array}$} \\
\hline & $N$ & $\%$ & $N$ & $\%$ \\
\hline \multicolumn{5}{|l|}{ Where do you usually buy or obtain the salt that is used for food in your house? } \\
\hline Purchase in a shop such as Pick 'n Pay, Shoprite, Spar, and general store & 135 & 67.5 & 124 & 78 \\
\hline Agricultural coarse salt obtained from a farmer, employer, cooperation, or elsewhere & 2 & 1 & 1 & 0.6 \\
\hline Spaza shop & 59 & 29.5 & 18 & 11.3 \\
\hline Informal sector: street vendor or hawker and a bag of maize meal & 4 & 2 & 14 & 8.2 \\
\hline Directly from a salt producer & 0 & 0 & 2 & 1.3 \\
\hline \multicolumn{5}{|c|}{ Where do you get salt if the salt used at school ran out before the service provider delivers the next batch? } \\
\hline Buy at a nearby shop/Spaza & 15 & 7.5 & 3 & 1.9 \\
\hline Fetch salt at home & 1 & 0.5 & 1 & 0.6 \\
\hline Do not add salt & 2 & 1 & 1 & 0.6 \\
\hline Never run out of salt & 182 & 91 & 15 & 96.9 \\
\hline \multicolumn{5}{|l|}{ Do you add more salt to your food because the salt is iodated? } \\
\hline Yes & 13 & 6.5 & 0 & 0 \\
\hline No & 122 & 61 & 67 & 42.1 \\
\hline Do not know & 6 & 3 & 3 & 1.9 \\
\hline Do not know what iodated salt is & 59 & 29.5 & 89 & 56 \\
\hline \multicolumn{5}{|l|}{ Do you have any concerns about iodine being added to table salt? } \\
\hline Yes & 17 & 8.5 & 3 & 1.9 \\
\hline No & 107 & 53.5 & 50 & 31.4 \\
\hline Unsure & 13 & 6.5 & 20 & 12.6 \\
\hline Do not know what iodine is & 63 & 31.5 & 86 & 54.1 \\
\hline \multicolumn{5}{|l|}{ In what kind of container do you store salt in the kitchen? } \\
\hline Plastic bag in which the salt was bought & 82 & 41 & 56 & 35.2 \\
\hline Carton box & 7 & 3.5 & 25 & 15.7 \\
\hline Rigid plastic container with holes at the top & 50 & 25 & 11 & 6.9 \\
\hline Open porcelain, wooden, plastic, or metal container with or without a lid & 61 & 30.5 & 67 & 42.1 \\
\hline \multicolumn{5}{|l|}{ How do you know the salt is Iodised? } \\
\hline Plastic bag/container with iodised salt written on it & 50 & 25 & 47 & 29.6 \\
\hline Salt having brown colour & 4 & 2 & 3 & 1.9 \\
\hline Salt with pure white colour & 34 & 17 & 27 & 17 \\
\hline Do not know & 112 & 56 & 82 & 51.6 \\
\hline \multicolumn{5}{|l|}{ When do you add iodised salt to food? } \\
\hline While cooking & 101 & 50.5 & 71 & 44.6 \\
\hline Start cooking with salt & 90 & 45 & 88 & 55.3 \\
\hline While eating & 3 & 1.5 & 0 & 0 \\
\hline Do not know & 6 & 3 & 0 & 0 \\
\hline
\end{tabular}


TABLE 5: Iodine nutrition knowledge test.

\begin{tabular}{|c|c|c|c|c|}
\hline \multirow{2}{*}{ Description of questions } & \multicolumn{2}{|c|}{ Mopani District } & \multicolumn{2}{|c|}{ Vhembe District } \\
\hline & $N$ & $\%$ & $N$ & $\%$ \\
\hline \multicolumn{5}{|l|}{ What is iodine? } \\
\hline Vitamin & 65 & 32.5 & 19 & 11.9 \\
\hline${ }^{*}$ Micronutrient/mineral & 58 & 29 & 50 & 31.5 \\
\hline Something in the food that we eat & 4 & 2 & 13 & 8.2 \\
\hline Other (medicine, potion, etc.) & 2 & 1 & 0 & 0 \\
\hline Do not know & 71 & 35.5 & 77 & 48.4 \\
\hline \multicolumn{5}{|l|}{ Main source of iodine } \\
\hline${ }^{*}$ Iodised salt/iodated salt & 12 & 6 & 73 & 45.9 \\
\hline Fish/sea food/marine food products & 60 & 30 & 29 & 18.2 \\
\hline Vegetables & 25 & 12.5 & 12 & 7.5 \\
\hline Meat or meat products & 25 & 12.5 & 6 & 3.7 \\
\hline Dairy products & 5 & 2.5 & 4 & 2.5 \\
\hline Drinking water & 13 & 6.5 & 3 & 1.5 \\
\hline Other & 22 & 11 & 1 & 0.6 \\
\hline Do not know & 14 & 7 & 11 & 6.9 \\
\hline Do not know what iodine is & 24 & 12 & 20 & 12.5 \\
\hline \multicolumn{5}{|l|}{ Part of the body that needs iodine } \\
\hline Liver & 42 & 21 & 47 & 29.6 \\
\hline${ }^{*}$ Thyroid gland/gland in the front of the neck & 40 & 20 & 24 & 15.1 \\
\hline Lungs & 24 & 12 & 30 & 18.9 \\
\hline Do not know & 94 & 47 & 58 & 36.5 \\
\hline \multicolumn{5}{|l|}{ Most harmful effect on health of children if they do not get enough iodine } \\
\hline Slow growth & 59 & 29.5 & 59 & 37.1 \\
\hline Goitre/enlarged thyroid gland/swollen neck & 22 & 11 & 22 & 13.8 \\
\hline${ }^{*}$ Brain damage or underdevelopment of the brain/low intelligence & 7 & 3.5 & 17 & 9.4 \\
\hline Cretinism & 2 & 1 & 1 & 0.6 \\
\hline Hypothyroidism & 0 & 0 & 1 & 0.6 \\
\hline Death & 1 & 0.5 & 1 & 0.6 \\
\hline Diabetes mellitus & 7 & 3.5 & 4 & 2.5 \\
\hline Do not know & 74 & 37 & 29 & 18.2 \\
\hline Do not know what is iodine & 26 & 13 & 25 & 15.7 \\
\hline Hypertension & 2 & 1 & 2 & 1.3 \\
\hline \multicolumn{5}{|l|}{ Do you read labelling on the food package to check salt content? } \\
\hline *Yes & 56 & 28 & 48 & 30.2 \\
\hline No & 108 & 54 & 85 & 53.5 \\
\hline Cannot read & 12 & 6 & 2 & 1.3 \\
\hline Do not know what iodine is & 24 & 12 & 24 & 15.1 \\
\hline \multicolumn{5}{|l|}{ What is the daily recommendation of iodine for school-attending children? } \\
\hline${ }^{*} 120 \mu \mathrm{g} / \mathrm{L}$ & 101 & 50.5 & 75 & 47.2 \\
\hline $150 \mu \mathrm{g} / \mathrm{L}$ & 18 & 9 & 14 & 8.8 \\
\hline $220 \mu \mathrm{g} / \mathrm{L}$ & 2 & 15 & 2 & 1.3 \\
\hline Do not know & 79 & 39.5 & 68 & 42.8 \\
\hline
\end{tabular}

* Correct response.

3.2. Salt Fortification. Majority of the food handlers in Mopani (67.5\%) and Vhembe (78\%) were buying salt from supermarkets. Almost all food handlers in Mopani and Vhembe indicated that they never ran out of salt. A total of $30.5 \%$ in Mopani and $42.1 \%$ in Vhembe stored salt in containers without lids. More than half of the food handlers in Mopani (56\%) and Vhembe (51.6\%) did not know how to identify iodiated salt (Table 4).

3.3. Iodine Nutrition Knowledge. Frequencies of food handlers' answers to the iodine-related questions are summarised in Table 5. A total of $29 \%$ in Mopani and almost a third (31.5\%) in Vhembe knew that iodine is a micronutrient. A few (6\%) food handlers in Mopani and almost half (45.9\%) in Vhembe could correctly identify iodated salt as the main source of iodine. Almost half of the food handlers in Mopani and 36.5\% in Vhembe did not know which part of the body needed iodine for functioning. A few in Mopani (3.5\%) and Vhembe (9.4\%) correctly identified brain damage as the most harmful effect on the health of children if they do not get enough iodine. Half in Mopani (50.5\%) and almost half in Vhembe (47.2\%) knew the daily recommendation of iodine for school-attending children (Table 5). 
TABLE 6: Iodine nutrition knowledge scores.

\begin{tabular}{|c|c|c|c|c|c|}
\hline \multirow{2}{*}{ Scores $(\%)$} & \multirow{2}{*}{ Interpretation } & \multicolumn{2}{|c|}{ Mopani district } & \multicolumn{2}{|c|}{ Vhembe district } \\
\hline & & $N$ & $\%$ & $N$ & $\%$ \\
\hline $0-29.9$ & Poor & 95 & 47.5 & 54 & 34 \\
\hline $30-49.9$ & Fair & 45 & 22.5 & 45 & 28.3 \\
\hline $50-69.9$ & Good & 54 & 27 & 49 & 30.8 \\
\hline $70-89.9$ & Very good & 5 & 2.5 & 8 & 5 \\
\hline $90-100$ & Excellent & 1 & 0.5 & 3 & 1.90 \\
\hline
\end{tabular}

The iodine nutrition knowledge of food handlers was poor with majority scores ranging from 0 to $29.9 \%$. The distribution of scores by food handlers is summarised in Table 6.

\section{Discussion}

An iodine concentration of $15-64.9 \mathrm{ppm}$ denotes that the salt is adequately iodised [18]. The results suggest that a majority of the salt samples in Mopani and Vhembe districts were adequately iodised.

A portion of samples was inadequately or noniodised or excessively iodised in the current study. One would expect all salt samples used for the NSNP to be adequately iodised; however, this was not the case in the current study. Inadequate iodine intake may result in a variety of disorders, termed iodine deficiency disorders (IDD), such as goitre, cretinism, spontaneous abortion, perinatal mortality, and heart failure [18, 20-22]. On the other hand, excess iodine may impair thyroid function [23]. Recently, a study [24] conducted in Limpopo Province has reported excess UIC in $\mathrm{SAC}$ which is a problem. A possible explanation for the variation in iodine concentration levels could be that, in South Africa, there is no proper monitoring of salt fortifications at production sites [25]. This may result in some salt producers underiodising and some overiodising as observed in the current study.

The use of adequately iodised salt for the NSNP in Mopani (71\%) and Vhembe (65\%) was below the international coverage of $90 \%$. It is noteworthy to assume that salt producers iodising salt at a concentration of more than 20 ppm contributes to the elimination of iodine deficiency [22].

The results of the current study indicated that food handlers in Mopani and Vhembe stored salt either in the plastic bag in which the salt was bought in or in containers with/without a lid. When iodised salt is not stored in closed plastic bags, sealed waterproof materials, or closed containers, iodine losses occur leading to reduction in the iodine content of salt before it is consumed [26].

Again, when improperly packed iodated salt is transported over long distances under humid conditions, it will attract moisture and become wet, dissolving and carrying the iodate to the bottom of the bag, and finally, it can be lost if the bag is porous to water $[27,28]$. Salt packed in such materials may lose as much as $75 \%$ of its iodine content over nine months. High-density polyethylene bags and polyethylene laminated bags are recommended for bulk packaging purposes [29]. Contrary to the results of the current study are the findings of a study conducted in Ethiopia where it was reported that most of the salt containers had covers at the household and the majority of caterers stored salt in a cool, dry area [30]. The iodine content of the salt remained constant, and its distribution remained uniform for many months when the salt is packed and kept dry, preferably in a cool place and away from sunlight [31]. Gebremariam et al. [32] also found that using packed salt at the household level was significantly associated with the availability of adequately iodised salt.

The results of the study suggest that there is limited iodine nutrition knowledge among the food handlers working for the NSNP, despite international efforts to eradicate IDD worldwide and the notable progress South Africa and other countries have made towards this goal. It can be concluded that these efforts have not yielded the expected growth regarding the iodine nutrition knowledge. The results of the current study have yielded similar results to studies conducted among the South African adult population [33], where it was found that the knowledge level of iodine nutrition is low, particularly among the low socioeconomic groups. The current study and studies conducted in the Bargarh District [34], Kashmir Valley [35] of India, and the Andaman and Nicobar Islands have demonstrated low levels of iodine nutrition knowledge among the general public. Low levels of iodine nutrition knowledge is evident in the current study since more than a third of participants in Mopani and almost half of those in Vhembe did not know what iodine is, a few knew that salt was the main source of iodine, and half did not know which part of the body required iodine for functioning. Although international efforts have been put in place to emphasise the consequences of iodine deficiency on brain damage, it is surprising to note that the food handlers were not aware that mental retardation may result from iodine deficiency. To close this IDD communication gap, which appears to inhibit the transfer of this message to the consumer level, Jooste Joubert [33] maintains that both educational and public health communication strategies are required. In Turkey, the percentage of women using iodised salt increased significantly during a 3-month regional educational mass media campaign [36], indicating that improved IDD knowledge may lead to a more widespread consumption of iodised salt [33].

Nutrition knowledge is the knowledge of nutrients and foods [37]. Good nutrition knowledge is a rudiment for healthy living. Therefore, adequate nutrition knowledge is needed when purchasing and preparing balanced meals [38]. Apart from purchasing and preparing meals, nutrition knowledge is extremely useful in an intervention 
programme [39]. However, poor nutrition knowledge affects food choices and dietary interventions and can possibly compromise [40] the purpose of the NSNP. A food handler or cook working for the NSNP needs to know the various nutrient contents of each food type, proper application derived from great ideas, and benefit maximisation [38]. Failure to acquire potential and competent nutrition knowledge by food handlers of the NSNP may jeopardise addressing the micronutrient deficiencies, which is one of the crucial aims of the NSNP that has been widely neglected [41].

\section{Conclusions}

Since the introduction of mandatory salt iodisation by 40-60 ppm in South Africa in 1995, substantial progress has been made to eliminate IDD. More than 20 years after the implementation of the USI program, the results of the study show that the international goal of $90 \%$ coverage is still far from being realised. In the IDD Newsletter [42] of November 2013, Jooste indicated that household coverage of adequately iodised salt in South Africa was greater than $77 \%$. Proper measures must be put in place to monitor fortification of salt at production sites. The results also show that food handlers have limited information about the iodine nutrition. Effective iodine nutrition education should be included in the training of food handlers.

\section{Abbreviations}

ICCIDD: International Council for Control of Iodine Deficiency Disorders

IDD: $\quad$ Iodine deficiency disorders

MI: $\quad$ Micronutrient initiative

NSNP: National School Nutrition Program

SAC: $\quad$ School-age children

UNICEF: United Nations Children's Fund

USI: Universal Salt Iodisation

WHO: World Health Organisation.

\section{Data Availability}

Data will be available on request.

\section{Ethical Approval}

The University of Venda (UNIVEN) Ethics Committee approved the study and an ethics certificate (SHS/16/NUT/ 01/1011) was issued. The Limpopo Provincial Department of Education granted permission for the study to be conducted. Furthermore, cooperation was sought from the Department of Education of Mopani and Vhembe districts, which gave clearance for the researcher to access the schools. The study was conducted in accordance with the principles of the Declaration of Helsinki [43] and the laws and regulations of South Africa.

\section{Consent}

The participating food handlers gave written informed consent.

\section{Conflicts of Interest}

The authors declare that they have no conflicts of interest.

\section{Authors' Contributions}

Ramugondo M, Mushaphi LF, and Mabapa NS were responsible for the design of the study. Mabapa NS was responsible for collecting data in the Vhembe District, and Ramugondo M collected data in the Mopani District. Mabapa NS was responsible for the statistical analysis and the paper version. Ramugondo $\mathrm{M}$ was responsible for testing iodine levels in salt. All authors read and approved the final manuscript.

\section{Acknowledgments}

The authors are grateful to all persons who helped in the collection of salt samples in the schools. They would like to thank Ms TD Ndou for interviewing the food handlers and food handlers for agreeing to participate in the study. They would also like to thank the Provincial Department of Education (DoE) for granting them permission to conduct the study; the DoE Vhembe District office for providing them with information on schools and giving them permission to visit the circuits; circuit managers for allowing them to visit the schools; and principals for allowing them to interview the food handlers. The authors thank the University of Venda Research and Ethic Committee for approving the study and the University of Venda for funding this project.

\section{References}

[1] World Health Organization, Oral Health Surveys: Basic Methods, World Health Organization, Geneva, Switzerland, 2013.

[2] World Hunger Education Service, World Hunger and Poverty Facts and Statistics, World Hunger Education Service, Washington, DC, USA, 2012.

[3] N. Nnakwe and G. Onyemaobi, "Prevalence of food insecurity and inadequate dietary pattern among households with and without children in imo state Nigeria," International Journal of Sociology and Anthropology, vol. 5, no. 9, pp. 402-408, 2013.

[4] E. Mabaya, D. Jordaan, P. Malope, M. Monkhei, and J. Jackson, "Attribute preferences and willingness to pay for fortified cereal foods in Botswana," Agrekon, vol. 49, no. 4, pp. 459-483, 2010.

[5] P. O. Iversen, L. du Plessis, D. Marais, M. Morseth, and M. Herselman, "Nutritional health of young children in South Africa over the first 16 years of democracy," South African Journal of Child Health, vol. 5, no. 3, pp. 72-77, 2011.

[6] S. P. Singh and D. R. Babu, "Nutritional status of primary school children in urban areas of Hyderabad, Andhra Pradesh, India," Journal of Community Nutrition \& Health, vol. 2, no. 1, p. 36, 2013.

[7] D. Bundy, S. Sheaffer, M. Jukes et al., School Based Nutrition Health Programs. Disease Control Priorities in Developing Countries, World Bank, Washington, DC, USA, 2nd edition, 2006.

[8] N. Nhlapo, R. J. Lues, E. Kativu, and W. H. Groenewald, "Assessing the quality of food served under a South African 
school feeding scheme: a nutritional analysis," South African Journal of Science, vol. 111, no. 1-2, pp. 1-9, 2015.

[9] K. C. Insel, G. O. Einstein, D. G. Morrow, and J. T. Hepworth, "A multifaceted prospective memory intervention to improve medication adherence: design of a randomized control trial," Contemporary Clinical Trials, vol. 34, no. 1, pp. 45-52, 2013.

[10] K. Kallman, Food for Thought: A Review of the National School Nutrition Programme, University of Cape Town, Cape Town, South Africa, 2005.

[11] D. Labadarios, N. P. Steyn, C. Mgijima, and N. Daldla, "Review of the South African nutrition policy 1994-2002 and targets for 2007: achievements and challenges," Nutrition, vol. 21, no. 1, pp. 100-108, 2005.

[12] L. H. Jomaa, E. McDonnell, and C. Probart, "School feeding programs in developing countries: impacts on children's health and educational outcomes," Nutrition Reviews, vol. 69, no. 2, pp. 83-98, 2011.

[13] F. Delange, "The disorders induced by iodine deficiency," Thyroid, vol. 4, no. 1, pp. 107-128, 1994.

[14] P. L. Jooste, "Assessment of the iodine concentration in table salt at the production stage in South Africa," Bulletin of the World Health Organization, vol. 81, pp. 517-521, 2003.

[15] S. A. Stats, "Statistics South Africa: Formal Census," 2011.

[16] P. Jooste, N. Upson, and K. Charlton, "Knowledge of iodine nutrition in the South African adult population," Public Health Nutrition, vol. 8, no. 4, pp. 382-386, 2005.

[17] South African National Food Consumption Survey, The Knowledge, Attitude, Behaviour and Procurement Regarding Fortified Foods, a Measure of Hunger and the Anthropometric and Selected Micronutrient Status of Children Aged 1-9 Years and Women of Child Bearing Age, University of Stellenbosch and Tygerberg Academic Hospital: Division of Human Nutrition, Stellenbosch, South Africa, 2005.

[18] F. Rohner, M. O. Kangambèga, N. Khan et al., "Comparative validation of five quantitative rapid test kits for the analysis of salt iodine content: laboratory performance, user-and fieldfriendliness," PLoS One, vol. 10, no. 9, 2015.

[19] D. Kartono, A. Atmarita, A. B. Jahari, S. Soekirman, and D. Izwardy, "The situation of urinary iodine concentration (UIC) among school age children, women at reproductive age and pregnant women in Indonesia: the analysis of Riskesdas 2013," Gizi Indonesia, vol. 39, no. 1, pp. 49-58, 2017.

[20] B. Hetzel, "Iodine deficiency disorders (IDD) and their eradication," The Lancet, vol. 322, no. 8359, pp. 1126-1129, 1983.

[21] World Health Organization/United Nations Children's Fund/ International Council for Control of Iodine Deficiency Disorders (WHO/UNICEF/ICCIDD), Assessment of the Iodine Deficiency Disorders and Monitoring Their Elimination, World Health Organization, Geneva, Switzerland, 2001.

[22] M. Li and C. J. Eastman, "The changing epidemiology of iodine deficiency," Nature Reviews Endocrinology, vol. 8, no. 7, pp. 434-440, 2012.

[23] A. M. Leung and L. E. Braverman, "Consequences of excess iodine," Nature Reviews Endocrinology, vol. 10, no. 3, pp. 136-142, 2014.

[24] E. Mabasa, N. Mabapa, P. Jooste, and X. Mbhenyane, "Iodine status of pregnant women and children age 6 to 12 years feeding from the same food basket in Mopani district, Limpopo province, South Africa," South African Journal of Clinical Nutrition, vol. 32, no. 3, pp. 76-82, 2019.

[25] J. Osei, M. Andersson, O. V. D. Reijden, S. Dold, C. M. Smuts, and J. Baumgartner, "Breast-milk iodine concentrations, iodine status, and thyroid function of breastfed infants aged 2-4 months and their mothers residing in a South African township," Journal of Clinical Research in Pediatric Endocrinology, vol. 8, no. 4, pp. 381-391, 2016.

[26] M. L. Sebotsa, A. Dannhauser, W. F. Mollentze, G. M. Mollentze, F. A. Mahomed, and P. L. Jooste, "Knowledge, attitudes and practices regarding iodine among patients with hyperthyroidism in the Free State, South Africa," South African Journal of Clinical Nutrition, vol. 22, no. 1, 2009.

[27] M. G. V. Mannar and J. T. Dunn, Salt Iodization for the Elimination of Iodine Deficiency, MI/ICCIDD/UNICEF/WHO, ICCIDD, The Netherlands, 1995, http://ign.org/cm_data/1995_ WHO_Salt_iodization_for_the_elimination_of_IDD.pdf.

[28] World Health Organization/United Nations Children's Fund/ International Council for Control of Iodine Deficiency Disorders (WHO/UNICEF/ICCIDD), Assessment of the Iodine Deficiency Disorders and Monitoring Their Elimination. A Guide for Programme Managers, World Health Organization, Geneva, Switzerland, 2007.

[29] V. D. Assey, "Controlling iodine deficiency disorders through salt iodation in Tanzania," 2009.

[30] L. Takele, T. Belachew, and T. Bekele, "Iodine concentration in salt at household and retail shop levels in Shebe town, south west Ethiopia," East African Medical Journal, vol. 80, no. 10, pp. 532-539, 2003.

[31] W. Davidson, M. Finalyson, and C. Watson, "Iodine deficiency disorder," The Journal of Agricultural Science, vol. 3, no. 1, p. 148, 2005.

[32] H. G. Gebremariam, M. E. Yesuf, and D. N. Koye, "Availability of adequately iodized salt at household level and associated factors in Gondar town, Northwest Ethiopia," ISRN Public Health, vol. 2013, Article ID 160582, 6 pages, 2013.

[33] P. L. Jooste and E. Joubert, "Iodine and goitre status of primary schoolchildren near Worcester in the Western Cape," South African Journal of Clinical Nutrition, vol. 17, no. 1, pp. 32-34, 2004.

[34] S. S. Mohapatra, G. Bulliyya, A. S. Kerketta, J. J. Geddam, and A. S. Acharya, "Elimination of iodine deficiency disorders by 2000 and its bearing on the people in a district of Orissa, India: a knowledge-attitude-practices study," Asia Pacific Journal of Clinical Nutrition, vol. 10, no. 1, pp. 58-62, 2001.

[35] A. H. Zargar, J. A. Shah, and B. A. Laway, "Prevalence of goitre and iodine deficiency in school children in anantnag (Kashmir Valley)," Annals of the National Academy of Medical Sciences (India), vol. 32, no. 2, pp. 97-104, 1996.

[36] G. Çan, A. Ökten, and J. Green, "The role of local mass media in promoting the consumption of iodized table salt," Health Education Research, vol. 16, no. 5, pp. 603-608, 2001.

[37] K. G. Grunert, J. Wills, L. F. Celemín, L. Lähteenmäki, J. Scholderer, and S. S. G. Bonsmann, "Socio-demographic and attitudinal determinants of nutrition knowledge of food shoppers in six European countries," Food Quality and Preference, vol. 26, no. 2, pp. 166-177, 2012.

[38] N. Kaliamoorth, "Poverty and malnutrition," Language in India, vol. 13, no. 4, pp. 67-78, 2013.

[39] K. Legbara and M. Selepe, "Nutrition knowledge of food handlers for national school nutrition programme (NSNP) in esikhaleni and Kwa- Dlangeza schools," African Journal of Hospitality, Tourism and Leisure, vol. 6, no. 4, 2017.

[40] M. A. Beydoun and Y. Wang, "Do nutrition knowledge and beliefs modify the association of socio-economic factors and diet quality among US adults?" Preventive Medicine, vol. 46, no. 2, pp. 145-153, 2008. 
[41] M. E. van Stuijvenberg, "Using the school feeding system as a vehicle for micronutrient fortification: experience from South Africa," Food and Nutrition Bulletin, vol. 26, no. 2, pp. S213-S219, 2005.

[42] P. L. Jooste, "South Africa: leading the way with 60 years of salt iodization: IDD Newsletter," 2013.

[43] Declaration of de Helsinki, "AMM: Ethical Principles for Medical Research Involving Human Subjects,” 2013, http:// www.wma.net/es/30publications/10policies/b3. 